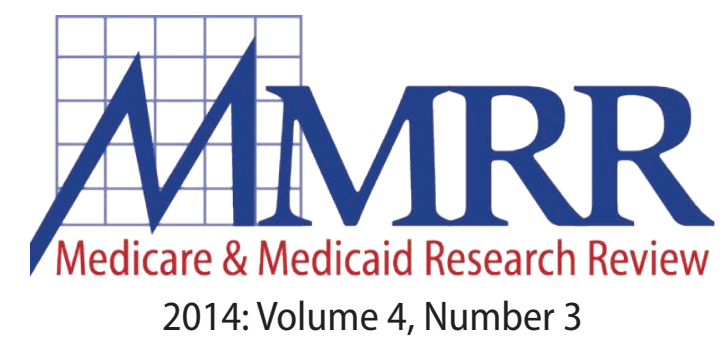

A publication of the Centers for Medicare \& Medicaid Services, Office of Information Products \& Data Analytics

\title{
Potential Medicaid Cost Savings from Maternity Care Based at a Freestanding Birth Center
}

\section{Embry Howell, Ashley Palmer, Sarah Benatar, and Bowen Garrett The Urban Institute-Health Policy Center}

Objectives: Medicaid pays for about half the births in the United States, at very high cost. Compared to usual obstetrical care, care by midwives at a birth center could reduce costs to the Medicaid program. This study draws on information from a previous study of the outcomes of birth center care to determine whether such care reduces Medicaid costs for low income women.

Methods: The study uses results from a study of maternal and infant outcomes at the Family Health and Birth Center in Washington, D.C. Costs to Medicaid are derived from birth center data and from other national sources of the cost of obstetrical care.
Results: We estimate that birth center care could save an average of $\$ 1,163$ per birth (2008 constant dollars), or $\$ 11.6$ million per 10,000 births per year. Conclusions: Medicaid is the leading payer for maternity services. As Medicaid faces continuing cost increases and budget constraints, policy makers should consider a larger role for midwives and birth centers in maternity care for low-risk Medicaid pregnant women.

Keywords: Cost effectiveness analysis, cost, utility, benefit cost, maternal and perinatal care and outcomes, birth centers, obstetrical costs, midwifery, Medicaid

ISSN: 2159-0354

doi: http://dx.doi.org/10.5600/mmrr.004.03.a06 


\section{Background}

Medicare \& Medicaid Research Review 2014: Volume 4, Number 3

\section{Mission Statement}

Medicare \& Medicaid Research Review is a peerreviewed, online journal reporting data and research that informs current and future directions of the Medicare, Medicaid, and Children's Health Insurance programs. The journal seeks to examine and evaluate health care coverage, quality and access to care for beneficiaries, and payment for health services.

\section{http://www.cms.gov/MMRR/}

\section{Centers for Medicare \& Medicaid Services Marilyn Tavenner Administrator}

Editor-in-Chief

David M. Bott, Ph.D.

The complete list of Editorial Staff and Editorial Board members may be found on the MMRR Web site (click link): $\underline{\text { MMRR Editorial Staff Page }}$

Contact: mmrr-editors@cms.hhs.gov

Published by the Centers for Medicare \& Medicaid Services.

All material in the Medicare \& Medicaid Research Review is in the public domain and may be duplicated without permission. Citation to source is requested.
The Medicaid program is a crucial payer for prenatal care, delivery, and newborn services. In 2008, Medicaid paid for 40 percent of births nationwide, rising to 48 percent by 2010 (Markus, Andres, West, Garro, \& Pellegrini, 2013). Yet states face an environment of rapidly increasing use of technology and escalating costs for obstetrical care. In particular, recent increases in Cesarean section and pre-term birth rates have contributed to higher costs for Medicaid and other payers (Martin et al., 2010; Bettegowda et al., 2008).

One option may be to provide midwifery care in freestanding birth centers for more Medicaid deliveries. Freestanding birth centers provide prenatal care and, when appropriate, delivery care at the birth center or at a hospital. There were 217 free-standing birth centers in 2011 in the U.S. ${ }^{1}$ A recent study showed that 30 of 44 states responding to a survey covered deliveries at birth centers under Medicaid (Ranji, Salganicoff, Stewart, Cox, $\&$ Doamekpor, 2009). In addition to potentially improving care for low-income women, birth center care may reduce costs compared to usual care (Schroeder et al., 2012). To date, the costs of birth center care for low-income women have not been rigorously evaluated in the United States.

Cost studies and comparative effectiveness research are becoming increasingly used for evaluating health services in the U.S. and abroad (Rawlins, 2013; Garber \& Sox, 2010; Russell, Gold, Siegel, Daniels, \& Weinstein, 1996; Chalkidou \& Anderson, 2009). Through such analyses, the outcomes and costs of alternative health services are compared in order to make a judgment about

${ }^{1}$ Personal communication with K. Bauer, American Association of Birth Centers, 2011. 
which is a better investment. However, both costs and effects are difficult to calculate accurately for a variety of reasons (Tan-Torres Edejer et al., 2003).

The first and more difficult challenge is measuring the impact of birth center care relative to usual care on factors that drive costs, in a manner that controls for differences in social risk, medical risk, and other differences in the women who receive care in the two settings. Women served in birth centers are generally at lower medical risk, and it would be inappropriate to compare costs without controlling for differences in risk. The second challenge is measuring the relevant components of costs, particularly the individual components that vary according to the type of maternity care received.

This paper provides new evidence of the cost of birth center care relative to usual care for lowincome women enrolled in Medicaid. It does this by estimating relevant cost components from a variety of data sources and applying the cost estimates to women receiving birth center care and women not receiving birth center care, but who have been reweighted to have nearly identical demographic characteristics and observed risk factors. The information in this paper is timely, because the Centers for Medicare \& Medicaid Services (CMS) recently launched a new national demonstration initiative, called Strong Start, to reduce the rate of early elective deliveries and to test the effectiveness of specific enhanced prenatal care approaches.

\section{Methods}

\section{Estimates of the Effect of Birth Center Care on Outcomes}

In order to estimate the effects of birth center care compared to usual care, we use findings from a prior quantitative case study of maternal and infant health outcomes at the Family Health and
Birth Center (FHBC) in Washington, D.C. More detail on the methods for the outcomes analysis is provided in another journal article (Benatar, Garrett, Howell, \& Palmer, 2013). The FHBC study uses propensity score reweighting methods to create a comparison group that, when weighted, has nearly identical observed characteristics as the birth center group. The study found that the FHBC led to lower C-section rates and lower rates of preterm delivery.

The FHBC study controls carefully for risk selection, which has been a problem in previous studies of birth center care. Risk selection can occur when women who choose to go to the birth center are at higher or lower risk for poor birth outcomes than the comparison group. Also, women may be transferred away from birth center care because they develop a health problem. Some previous studies have excluded such transfers from the birth center sample. In addition, some studies have included only women who deliver at the birth center, which excludes women with high-risk hospital deliveries. In this study, all women who delivered singleton births with a gestational age of at least 24 weeks and received a minimum of two prenatal visits at the birth center between 2005 and 2008 are included in the "birth center care" group $(\mathrm{N}=875){ }^{2}$ The birth center group retains women ever followed at the birth center, regardless of where they delivered (hospital or birth center). Birth certificate data were matched to a list of birth center clients, providing data on outcomes.

A "usual care" comparison group was constructed using birth certificate data for other women who gave birth in the District of Columbia during the study period (2005-2008). Women who had fewer than two prenatal visits or who delivered at less than 24 weeks gestation were excluded

\footnotetext{
${ }^{2}$ We include all who had two visits, since the first visit is usually not a visit for prenatal care, but rather an information session.
} 
from the comparison group, since there are no women with those characteristics in the birth center sample. The birth certificate variables used in the propensity score model include maternal education, race/ethnicity, maternal age, parity, zip code of residence, and medical risk factors prior to pregnancy. Propensity score reweighting was used to construct a weighted sample with nearly the same distribution of observable characteristics as the birth center group. To address potential selection related to unobserved differences between the two groups of women, we conducted sensitivity analysis using an instrumental variables approach and found essentially the same impact of birth center care on outcomes as the propensity score analysis. More information about the methods and results from the FHBC study is contained in Benatar et al., (2013).

\section{Estimates of the Cost of Birth Center Care and Usual Care}

We use the outcomes experience from the birth center group and the matched usual care comparison group, along with a variety of proxy measures of Medicaid costs nationally in 2008, to estimate what national Medicaid savings would be if low-risk Medicaid obstetrical care was provided with the midwifery model of care used at the FHBC. Costs are estimated from the Medicaid payer perspective and do not include all societal costs.

Exhibit 1 shows the approach to estimating four types of cost, which are the major cost components for the obstetrical episode (which includes prenatal care, delivery, and postpartum care). These include physician costs, midwife costs, maternal and infant hospital costs, and birth center costs. Hospital costs include all hospital facility and personnel costs that are charged to Medicaid. Average hospital costs also include estimated neonatal intensive care unit (NICU) costs for both cohorts of women, using the infant gestational age at birth derived from birth certificate data. ${ }^{3}$ National costs for birth center care are not available, so estimates come from the Family Health and Birth Center. This could lead to an overestimate of birth center costs nationally, since average health costs per capita in the District of Columbia were higher than all other states in 2009 (Kaiser Family Foundation, 2013).

While these are the major components of the cost of care, there are other smaller cost components for which data are not available. For example, the hospital cost data do not detail transportation costs. Since inpatient care dominates the cost of the obstetrical episode, the effect of this exclusion is small.

For usual care, all women are assumed to be cared for by physicians throughout pregnancy and delivery. For birth center care, women delivering vaginally are assumed to be followed by midwives throughout pregnancy and delivery. Using the experience of the FHBC, 81.5 percent of them are assumed to deliver at a hospital, while the remainder deliver at the birth center. The costs of birth center women who deliver via Cesarean section are assumed to be the same as women who receive usual care.

When we have limited or no national data, we have taken an approach that minimizes differences between usual and birth center care. Therefore, the resulting estimate of the per-delivery cost differences between birth center and usual care is likely an underestimate.

\section{Findings}

Exhibit 2 compares differences in outcomes for birth center care and usual care, derived from propensity score reweighting. As shown, women receiving

\footnotetext{
${ }^{3}$ We did not consider the higher costs for babies born before 33 weeks of age, since it is less likely that birth center care could impact delivery in that early pre-term period. More detail on costestimation is available from authors on request.
} 
Exhibit 1. Methods for Estimating 2008 Cost to Medicaid for Birth Center Care and Usual Care

\begin{tabular}{|c|c|c|c|}
\hline Cost Category & Definition & Source & Estimation Approach \\
\hline Physician Costs & $\begin{array}{l}\text { National average } \\
\text { Medicaid physician } \\
\text { fees for prenatal care, } \\
\text { delivery, and postnatal } \\
\text { care in 2008, separately } \\
\text { for vaginal (CPT code } \\
59400 \text { ) and Cesarean } \\
\text { section delivery (CPT } \\
\text { code 59510). }\end{array}$ & $\begin{array}{l}\text { Zuckerman, S., Williams, } \\
\text { A., \& Stockley, K. (2009). } \\
\text { Trends in Medicaid } \\
\text { physician fees, 2003-2008. } \\
\text { Health Affairs, 28(3), } \\
\text { 510-519. }\end{array}$ & $\begin{array}{l}\text { These amounts are used to } \\
\text { estimate physician care } \\
\text { Medicaid costs for the usual care } \\
\text { group and for the birth center } \\
\text { women who have Cesarean } \\
\text { sections, since their delivery } \\
\text { would be performed by a } \\
\text { physician. Costs for deliveries for } \\
\text { birth center women are assumed } \\
\text { to be by midwives. }\end{array}$ \\
\hline Midwife Costs & $\begin{array}{l}\text { Prenatal, delivery, and } \\
\text { postnatal care for } \\
\text { vaginal delivery, at } \\
\text { either the birth center } \\
\text { or the hospital, for } \\
\text { women cared for at } \\
\text { birth centers. }\end{array}$ & $\begin{array}{l}\text { Centers for Medicare \& } \\
\text { Medicaid Services. (2010). } \\
\text { Information for Medicare } \\
\text { Fee-for-Service Health } \\
\text { Care Professionals. MLN } \\
\text { Matters Bulletin. }\end{array}$ & $\begin{array}{l}\text { There are no national data for } \\
\text { birth center midwife Medicaid } \\
\text { charges or costs. In } 2008 \text {, } \\
\text { CMS guidelines required that } \\
\text { Medicaid pay the lesser of } 80 \% \\
\text { of the charge or } 65 \% \text { of the } \\
\text { Medicare physician fee. } \\
\text { Nationally, Medicaid fees for } \\
\text { obstetrics are } .93 \text { of Medicare. We } \\
\text { use the formula: Midwife rate= } \\
\left.\text { [(Medicaid MD rate/ .93) }{ }^{*} .65\right] \text { to } \\
\text { estimate this cost. }\end{array}$ \\
\hline $\begin{array}{l}\text { Maternal and } \\
\text { Infant Hospital } \\
\text { Costs }\end{array}$ & $\begin{array}{l}\text { Average cost per hospital } \\
\text { stay for vaginal delivery } \\
\text { (DRG 765-766), } \\
\text { Cesarean delivery (DRG } \\
\text { 774-775), normal } \\
\text { newborns (DRG 795), } \\
\text { and the NICU for usual } \\
\text { care women and birth } \\
\text { center women who } \\
\text { deliver at a hospital. }\end{array}$ & $\begin{array}{l}\text { Maternal and normal } \\
\text { newborn cost for } \\
\text { Medicaid women and } \\
\text { infants: National Inpatient } \\
\text { Sample (NIS) maintained } \\
\text { by AHRQ HCUPnet } \\
\text { (http://hcupnet.ahrq.gov/) } \\
\text { NICU costs: Personal } \\
\text { communication with J. } \\
\text { Muri, National Perinatal } \\
\text { Information Center, } \\
\text { Providence, RI, February } \\
\text { 17, 2011. }\end{array}$ & $\begin{array}{l}\text { The hospital cost for mother } \\
\text { and newborn includes the cost } \\
\text { of all billed hospital services. } \\
\text { Maternal and normal newborn } \\
\text { charges are multiplied by } \\
\text { the cost-to-charge ratio for } \\
\text { the hospital where a woman } \\
\text { delivered. }{ }^{1} \text { For low birth weight } \\
\text { infants over } 32 \text { weeks gestation, } \\
\text { we estimated the cost of the } \\
\text { NICU by using data on the rate } \\
\text { of NICU use, and associated } \\
\text { charges is estimated for infants } \\
\text { over } 32 \text { weeks gestation-the } \\
\text { period most affected by birth } \\
\text { center care. These charges } \\
\text { are multiplied by the average } \\
\text { national NICU cost-to-charge } \\
\text { ratio. See Appendix Exhibit } \\
\text { A1 for more detail on the } \\
\text { calculation of NICU costs. }\end{array}$ \\
\hline
\end{tabular}

(Continued) 
Exhibit 1 Continued. Methods for Estimating 2008 Cost to Medicaid for Birth Center Care and Usual Care

\begin{tabular}{llll}
\hline Cost Category & \multicolumn{1}{c}{ Definition } & \multicolumn{1}{c}{ Source } & \multicolumn{1}{c}{ Estimation Approach } \\
\hline Birth Center & Average cost of care & American Association of & Average total charges (cost-to- \\
Costs & $\begin{array}{l}\text { and delivery at a birth } \\
\text { center for mother and }\end{array}$ & Birth Centers, 2007 and & charge ratios do not exist for birth \\
& newborn. & & $\begin{array}{l}\text { center care). }{ }^{2} \text { The newborn charge } \\
\text { is from the FHBC; national data }\end{array}$ \\
& & & are unavailable for newborn care. \\
\hline
\end{tabular}

NOTES: ${ }^{1}$ While this method estimates costs and not Medicaid payments, according to one study Medicaid payments are 89 percent of hospital costs on average, nationally in 2008 (American Hospital Association. (2009). Underpayment by Medicare and Medicaid Fact Sheet. Washington, DC: American Hospital Association.)

${ }^{2}$ According to a review of financial reports for the Family Health and Birth Center, birth center costs exceed charges for Medicaid and associated managed care plans.

SOURCE: Authors' analyses.

usual care are significantly more likely to have a Cesarean section (29.4 percent vs. 19.7 percent) and less likely to have a vaginal birth after Cesarean section (9.4 percent vs. 26.7 percent). Also, their lower rate of weekend delivery suggests that more usual care deliveries are scheduled (i.e., either induced or delivered by scheduled Cesarean section) than birth center births, which are almost evenly distributed across the days of the week. Women receiving usual care are significantly more likely to deliver preterm (11.0 vs. 7.9 percent) primarily due to a higher prevalence of late preterm delivery, and they have lower birth weight infants on average for all preterm births (3166 grams vs. 3245 grams) and for term births (3282 grams vs. 3325 grams).

Exhibit 3 shows the resulting cost estimates for each study group under usual care and birth center care. Estimated costs are shown separately for vaginal and Cesarean deliveries under either form of care and vaginal delivery cost estimates are separated by location-hospital or birth center-within the birth center care group only. Cost components include: maternal facility costs, infant facility costs, and physician or mid-wife

Exhibit 2. Differences in Outcomes Between Usual Care and Birth Center Care

\begin{tabular}{|c|c|c|c|}
\hline & $\begin{array}{l}\text { Usual Care } \\
(\mathrm{N}=42,987)\end{array}$ & $\begin{array}{l}\text { Birth Center } \\
\text { Care }(\mathrm{N}=872)\end{array}$ & ODDS RATIOS \\
\hline \multicolumn{4}{|l|}{ Delivery Outcomes } \\
\hline Cesarean Delivery & $29.3 \%$ & $19.8 \%$ & $0.59^{*}$ \\
\hline Vaginal Birth after Cesarean ${ }^{\star *}$ & $9.4 \%$ & $26.7 \%$ & $3.50^{*}$ \\
\hline Weekend Delivery & $23.9 \%$ & $28.6 \%$ & $1.28^{*}$ \\
\hline \multicolumn{4}{|l|}{ Infant Outcomes } \\
\hline Preterm & $11.0 \%$ & $7.9 \%$ & $0.70^{*}$ \\
\hline Average Birth Weight (grams) & $3166 \mathrm{~g}$ & $3245 g^{\star}$ & - \\
\hline Average Birth Weight at Term (grams) ${ }^{* * *}$ & $3282 \mathrm{~g}$ & $3325 g^{*}$ & - \\
\hline \multicolumn{4}{|c|}{ NOTES: ${ }^{\star}$ Difference between usual and birth center care is significant, $\mathrm{p}<.01$. } \\
\hline \multicolumn{4}{|c|}{$\begin{array}{l}\text {-The marginal effect for average birth weight was } 79 \text {, and the marginal effect for average birth weight at term was } 43 \text {. Both were statistically } \\
\text { significant at the } .01 \text { level. }\end{array}$} \\
\hline \multicolumn{4}{|c|}{ SOURCE: Benatar, S., Garrett, B., Howell, E. M., Palmer, A. (2013). Midwifery Care At A Freestanding Birth Center: A Safe and Effective } \\
\hline
\end{tabular}


Exhibit 3. Estimated Cost to Medicaid for Prenatal and Delivery Care for Women Served at Birth Centers and for Usual Care (Average Cost per Delivery), 2008

\begin{tabular}{lcccc}
\hline & $\begin{array}{c}\text { Infant } \\
\text { Facility } \\
\text { Costs }\end{array}$ & $\begin{array}{c}\text { Maternal } \\
\text { Facility } \\
\text { Costs }\end{array}$ & $\begin{array}{c}\text { MD or } \\
\text { Midwife } \\
\text { Costs }\end{array}$ & $\begin{array}{c}\text { Average } \\
\text { Cost of Care }\end{array}$ \\
\hline $\begin{array}{l}\text { Study Group } \\
\text { Usual Care (\% of births) }\end{array}$ & $\$ 2,149$ & $\$ 2,988$ & $\$ 1,331$ & $\$ 6,468$ \\
$\quad$ Vaginal Birth (70.7\%) & $\$ 2,258$ & $\$ 5,331$ & $\$ 1,434$ & $\$ 9,023$ \\
$\quad$ Cesarean Birth (29.3\%) & & & & $\$ 7,218$ \\
$\quad$ Average Total Medicaid Cost & & & & \\
Birth Center Care (\% of births) & $\$ 2,049$ & $\$ 2,988$ & $\$ 930$ & $\$ 5,967$ \\
$\quad$ Vaginal Birth at Hospital (61.7\%) & $\$ 250$ & $\$ 2,007$ & $\$ 930$ & $\$ 3,187$ \\
$\quad \begin{array}{l}\text { Vaginal Birth at Birth Center (18.5\%) } \\
\text { Cesarean Birth at Hospital (19.8\%) }\end{array}$ & $\$ 2,240$ & $\$ 5,331$ & $\$ 1,434$ & $\$ 9,005$ \\
$\quad$ Average Total Medicaid Cost & & & & $\$ 6,055$ \\
Difference between Usual Care and Birth Center Care & & & $\$ 1,163$ per delivery \\
\hline SOURCE: See Exhibit 1 for explanation of sources and calculations. & & &
\end{tabular}

costs (for the entire obstetrical episode, including prenatal, delivery, and post-partum care). NICU costs are included, as estimated from the gestational age distribution for each study group (see Appendix Exhibit A1).

The most expensive cost component is the maternal facility cost, whether the birth is at a birth center or a hospital. This varies from $\$ 2,007$ for a vaginal birth at the birth center to $\$ 5,331$ for a Cesarean delivery at a hospital under either form of care. Infant facility costs do not vary a great deal for within-hospital births under either form of care, but are much less for an infant born vaginally in a birth center, where the infant and mother do not stay overnight. Another important variation is the difference for vaginal delivery between usual care $(\$ 1,331)$ and birth center care $(\$ 930)$.

The result is an average cost estimate for a Medicaid delivery nationally in 2008 at $\$ 7,218$, while the average for a woman followed at a birth center is estimated to be $\$ 6,055$. This leads to an estimated average Medicaid cost-saving of $\$ 1,163$ per delivery, a 16 percent reduction when compared to usual care.
It is important to investigate what drives these savings in order to understand how policies could be changed to reduce costs and improve outcomes. There are four components of the cost difference between usual and birth center care: (1) differences in Cesarean section rates; (2) differences in the gestational age distribution of late pre-term and early term births and their associated NICU costs; (3) lower payments to midwives than to physicians; and (4) the cost of delivery at a birth center compared to a hospital delivery. Estimates of the savings from each component are derived from holding other differences constant and assuming no difference between the study and comparison group for the component being measured. For example, for the first cost component, Cesarean section rates are assumed to be identical between the two study groups, and the resulting cost saving is subtracted from $\$ 1,163$ in order to estimate the savings from differences in Cesarean section rates.

As shown in Exhibit 4, the largest component of the cost difference (45.8 percent) comes from a small group of deliveries, those delivered at the 


\begin{tabular}{lccc}
\hline Source & & \multicolumn{1}{c}{$\begin{array}{c}\text { Total Cost Savings } \\
\text { per 10,000 Medicaid } \\
\text { Deliveries (Millions) }\end{array}$} \\
\hline Differences in Cesarean Section Rates & Medicaid Cost Savings (\%) & $\begin{array}{l}\text { (21.0\%) } \\
\text { Differences in Gestational Age Distribution }\end{array}$ \\
Lower Payments to Midwives & $\$ 65$ & $(5.6 \%)$ & $\$ 0.65$ \\
Delivery at Birth Center Facility vs. Hospital & $\$ 322$ & $(27.7 \%)$ & $\$ 3.22$ \\
Total & $\$ 533$ & $(45.8 \%)$ & $\$ 5.33$ \\
\hline
\end{tabular}

SOURCE: Author's calculations.

birth center. Women and their infants do not stay overnight at the birth center. Rather they go home soon after delivery. Referring back to Exhibit 3, it is evident that the majority of the cost difference for this component comes from the much lower maternal and infant facility costs for such births.

The next two important components of the cost difference are lower payments to midwives vs. physicians (27.7 percent of the difference) and lower rates of Cesarean section for birth center births (21.0 percent of the cost difference). Only a small percent of the cost savings (5.6 percent) is due to the lower rate of late prematurity and early term birth in the birth center group (leading to lower NICU costs for births after 32 weeks gestation).

\section{Discussion}

This study has compared the outcomes and Medicaid costs for prenatal and delivery care provided at a freestanding birth center to those of usual obstetrical care for a carefully matched comparison group. We find that the outcomes (prematurity, birth weight, and rates of Cesarean section) were better on average for the birth center group and that average costs were lower by $\$ 1,163$ per delivery.

Because of the large volume of Medicaid-funded births nationally, a per-delivery savings of just over a thousand dollars is a large total potential savings to the program, should all low-risk births be shifted into an alternative prenatal care and delivery setting that achieves a similar level of savings. The sources of the cost difference between usual and birth center care have implications for the types of interventions that could lead to similar (or higher) savings among Medicaid births nationally. To achieve the full savings, it would be necessary to: (1) reduce Cesarean section rates among Medicaid births; (2) pay delivery providers at the rate of midwives and/or increase the proportion of deliveries by midwives; (3) shift more deliveries to a setting where mothers and their infants do not remain overnight; and (4) reduce late preterm and early term delivery.

\section{Reducing Cesarean Section Rates}

Rates of Cesarean section in the United States are higher than most other developed countries (Organization for Economic Co-operation and Development, 2013) and have risen since 2000 (Menacker \& Hamilton, 2010). States have documented a similar trend for Medicaid births (California Department of Health Care Services, Research and Analytic Studies Section 2010). This rise in the Cesarean section rate has led to a Healthy People 2020 goal of reducing Cesarean births among low-risk women (Healthy People, 2013). Some past efforts to reduce the rate have been successful (Flamm, Berwick, \& Kabcenell, 1998; Chaillet \& Dumont, 2007), but the rate continues 
to rise. Professional standards have changed, and babies that might have previously been delivered vaginally are now delivered by Cesarean section (Declercq, Menacker, \& MacDorman, 2006). Several experts have noted a shift in norms towards higher use of technology at birth (McCourt et al., 2007; MacDonald, 2011). Cesarean section is generally safe, although not as safe as vaginal delivery unless indicated by complications (Declercq et al., 2007). A scheduled Cesarean section can be convenient for obstetricians, other hospital personnel, and the family, yet the cost is about 50 percent higher for Medicaid than for a vaginal birth (see Exhibit 3).

It is evident from the results of the FHBC study that deliveries managed by midwives practicing in a birth center have lower rates of Cesarean section, even when the large majority of the infants are delivered in a hospital rather than a freestanding birth center. Replicating these findings requires that the prenatal and delivery care providers for Medicaid women adopt norms for managing a low-risk delivery that are similar to those used by FHBC midwives-i.e., a lower technology model of care. Expanding the rate of midwifery care, either inside or outside birth centers, is an important potential policy initiative for Medicaid, although many barriers exist (Goodman, 2007).

\section{Shifting the Gestational Age Distribution Through Reduced Scheduling of Delivery}

Reducing the rate of induction and scheduled Cesarean section is a goal of the March of Dimes (2011) as a means of reducing late prematurity. While only a small portion of the cost differences between birth center care and usual care are due to reduced NICU costs for birth center deliveries, improvements in the gestational age distribution are worthwhile for other reasons. One component of the federal Strong Start initiative is to reduce unnecessary inductions for Medicaid women.

\section{Lowering the Rate Paid to Obstetrical Providers}

Lowering provider payments is a common policy alternative for Medicaid programs. However, this alternative will likely meet with stiff opposition from both midwives (who would like to be paid on par with obstetricians) and physicians. Indeed, increased Medicaid reimbursement to physicians has been used as a policy to improve provider participation, increasing access to prenatal care for Medicaid women. Thus, achieving substantial savings through reduced obstetrical provider fees is an unlikely policy alternative except as combined with expanded use of midwifery for normal pregnancies and deliveries.

\section{Delivery in a Birth Center Where Women and Infants Go Home on the Day of Delivery}

Exhibit 4 shows that the most important component of cost savings derives from differential facility fees. These fees are substantially lower for birth center vaginal deliveries, where mothers and infants are discharged in less than 24 hours. Only 18.6 percent of women who receive some prenatal care at the FHBC elect to deliver at the birth center, but this group is responsible for almost half the overall cost savings. For those women who receive prenatal care at the birth center, but deliver (with birth center midwives) at the hospital, the cost impact is smaller, primarily attributed to different Cesarean section rates. Not all costs at the FHBC are covered by Medicaid fees (some are covered by grants and donations). Consequently, had Medicaid covered all birth center costs, the total Medicaid cost for birth center women would be somewhat higher.

While the first three policy alternatives (reduced rates of Cesarean section, reduced scheduling of deliveries, and reduced provider payments) could possibly be achieved without 
expanding birth centers, it is unlikely that the major savings from birth centers (reduced facility fees) would be achieved without a shift to birth center deliveries. A previous initiative to reduce the length of the delivery hospital stay quickly became politically contentious (Declercq \& Simmes, 1997). Thus, an expansion of birth center care should be carefully considered and done through demonstrations that examine maternal and infant outcomes and costs. This is currently underway through the national evaluation of the CMS-funded Strong Start demonstration program.

\section{Financial Sustainability of Birth Centers}

The Medicaid program could consider how to subsidize freestanding birth centers in order to achieve the improved outcomes of reduced Cesarean sections and reduced scheduled deliveries. This could include, for example, some form of cost-based reimbursement, such as for federally qualified health centers (FQHCs). On the other hand, such subsidies would reduce the savings to the Medicaid program.

\section{Limitations}

There are several important limitations to this study. Most importantly, the data are based on results from a single observational study and should be replicated. In addition, while propensity score reweighting is used to develop the comparison group, and instrumental variable analysis is used as a sensitivity analysis, it is certainly possible that we do not control adequately for differences in risk. If the comparison group is at higher risk, our estimated cost differences are biased. For example, some women choose to have an elective Cesarean section and, thus, would not go to the birth center for prenatal care. They elevate the rate of Cesarean section deliveries in the comparison group to an unknown degree. The propensity score reweighting process is designed to produce a weighted comparison group of women at similarly low risk, but the method can only make the treatment and comparison groups similar on the limited number of clinical outcomes and other factors included in the birth certificate data. Finally, the cost data may be biased to an unknown degree. Some costs were excluded due to lack of data, such as transportation costs from the birth center to the hospital in the case of a complication. However, transportation costs are not high compared to the costs of hospitalization, which is included. Also, we did not have follow-up data to track outcomes and costs after delivery, such as the cost of readmission shortly after birth, for neither the study nor comparison group. Costs were estimated as described above using national averages rather than the specific costs for individual women.

\section{Conclusion}

In summary, should the outcomes from the Family Health and Birth Center be replicable nationally, the birth center model of care could have a substantial impact on the cost of the Medicaid obstetrical episode, achieving on average a 16 percent reduction in costs for every pregnancy followed at a birth center (when compared to usual care), or \$11.64 million for every 10,000 Medicaid deliveries. However, an analysis of the components of this cost savings shows that achieving such a substantial savings is fraught with challenges. In addition, it will be important to replicate these findings through the expansion of the study to the evaluation of the cost of care in the large number of birth centers around the country that are participating in the Strong Start initiative. 


\section{Disclaimer}

The authors have no conflicts of interest related to this analysis. The content of this article is solely the responsibility of the authors and does not necessarily reflect the views of the Department of Health and Human Services.

\section{Correspondence}

Embry Howell, Ph.D., The Urban Institute, Health Policy Center, 2100 M St. NW, Washington, DC, 20037, EHowell@urban.org, Tel.202-261-5714

\section{Acknowledgment}

We acknowledge the advice and help of the Family Health and Birth Center staff in Washington, D.C., particularly Ruth Lubic, the founder, and of the D.C. Department of Health staff who provided data.

\section{References}

Benatar, S., Garrett, B., Howell, E. M., \& Palmer, A. (2013). Midwifery Care at a Freestanding Birth Center: A Safe and Effective Alternative to Conventional Maternity Care. Health Services Research. doi: http://dx.doi.org/10.1111/14756773.12061 PubMed

Bettegowda, V. R., Dias, T., Davidoff, M., Damus, K., Callaghan, W., \& Petrini, J. (2008). The Relationship Between Cesarean Delivery and Gestational Age Among U.S. Singleton Births. Clinics in Perinatology, 35(2), 309-323. PubMed

California Department of Health Care Services, Research and Analytic Studies Section (2010). Medi-cal Birth, calendar year 2006. Sacramento, CA: California Department of Health Care Services.

Chalkidou, K., \& Anderson, G. (2009). Comparative effectiveness research: international experiences and implications for the United States. Washington, DC: AcademyHealth.
Chaillet, N., \& Dumont, A. (2007). Evidence-Based Strategies for Reducing Cesarean Section Rates: A Meta-Analysis. Birth (Berkeley, Calif.), 34(1), 53-64. PubMed http://dx.doi.org/10.1111/ j.1523-536X.2006.00146.x

Declercq, E., \& Simmes, D. (1997). The Politics of "Drive-Through Deliveries:" Putting Early Postpartum Discharge on the Legislative Agenda. The Milbank Quarterly, 75(2), 175-202. PubMed http://dx.doi.org/10.1111/1468-0009.00051

Declercq, E., Menacker, F., \& MacDorman, M. (2006). Maternal Risk Profiles and the Primary Cesarean Rate in the United States, 1991-2002. American Journal of Public Health, 96(5), 867-872. PubMed http://dx.doi.org/10.2105/ AJPH.2004.052381

Declercq, E., Barger, M., Cabral, H. K., Evans, S. R., Kotelchuck, M., Simon, C., Heffner, L. J. (2007). Maternal Outcomes Associated with Planned PrimaryCesarean BirthsCompared with Planned Vaginal Births. ObstetricsandGynecology, 109(3), 669-677. PubMed http://dx.doi.org/10.1097/01. AOG.0000255668.20639.40

Flamm, B. L., Berwick, D., \& Kabcenell, A. (1998). Reducing Cesarean Section Rates Safely: Lessons from a "Breakthrough Series" Collaborative. Birth (Berkeley, Calif.), 25(2), 117-124. PubMed http://dx.doi.org/10.1046/ j.1523-536x.1998.00117.x

Garber, A. M., \& Sox, H. C. (2010). The Role of Costs in Comparative Effectiveness Research. Health Affairs, 29(10), 1805-1811. PubMed http://dx.doi.org/10.1377/hlthaff.2010.0647

Goodman, S. (2007). Piercing the Veil: The Marginalization of Midwives in the United States. Social Science \& Medicine, 65(3), 610-621. PubMed http://dx.doi.org/10.1016/j.socscimed. 2007.03.052 
Healthy People (2013). Maternal, Infant, and Child Health Objectives. Washington, DC: Office of Disease Prevention and Health Promotion. Retrieved from http://www.healthypeople. gov/2020/topicsobjectives2020/overview. asp ? topicid $=26$

Kaiser Family Foundation (2013). Health Care Expenditures per Capita by State of Residence. State Health Facts. Retrieved from http://kff.org/other/state-indicator/healthspending-per-capita

March of Dimes (2011). Annual report 2010. White Plains, NY:March of Dimes. Retrieved from http:// www.marchofdimes.com/downloads/2010_ Annual_Report.pdf

Markus, A. R., Andres, E., West, K. D., Garro, N., \& Pellegrini, C. (2013). Medicaid Covered Births, 2008 Through 2010, in the Context of the Implementation of Health Reform. Women's Health Issues, 23(5), e273-e280. PubMed http://dx.doi.org/10.1016/j.whi.2013.06.006

Martin, J. A., Hamilton, B. E., Sutton, P. D., Ventura, M. A., Matthews, T. J., \& Osterman, M. J. K. (2010). Births: Final Data for 2008. [Hyattsville, MD: National Center for Health Statistics.]. National Vital Statistics Reports, 59(1), 1-72. PubMed

McCourt, C., Weaver, J., Statham, H., Beake, S., Gable, J., \& Creedy, D. (2007). Elective Cesarean Section and Decision Making: A Critical Review of the Literature. Birth (Berkeley, Calif.), 34(1), 65-79. PubMed http://dx.doi.org/10.1111/ j.1523-536X.2006.00147.x

MacDonald, M. E. (2011). The Cultural Evolution of Natural Birth. Lancet, 378(9789), 394-395. PubMed http://dx.doi.org/10.1016/ S0140-6736(11)61200-2
Menacker, F., \& Hamilton, B. E. (2010). Recent Trends in Cesarean Delivery in the United States. U.S. National Center for Health Statistics (Data Brief, No. 35). Atlanta, GA: Center for Disease Control and Prevention.

Organization for Economic Co-operation and Development (2013). OECD health data, 2013. Retrieved from www.oecd.org/els/healthsystems/Health-at-a-Glance-2013.pdf

Ranji, U., Salganicoff, A., Stewart, A., Cox, M., \& Doamekpor, L. (2009). State Medicaid coverage of perinatal services: Summary of state survey findings. Washington, DC: The Kaiser Family Foundation and George Washington University. Rawlins, M. D. (2013). NICE: Moving Onward. The NewEnglandJournalof Medicine, 369,3-5. PubMed http://dx.doi.org/10.1056/NEJMp1303907

Russell, L. B., Gold, M. R., Siegel, J. E., Daniels, N., \& Weinstein, M. C. (1996). The Role of CostEffectiveness Analysis in Health and Medicine. Journal of the American Medical Association, 276(14), 1172-1177. PubMed http://dx.doi. org/10.1001/jama.1996.03540140060028

Schroeder, E., Stavros, P., Patel, N., Hollowell, J., Puddicombe, D., Redshaw, M., \& Brocklehurst, P. (2012). Cost Effectiveness of Alternative Planned Places of Birth in Woman at Low Risk of Complications: Evidence From the Birthplace in England National Prospective Cohort Study. British Medical Journal, 344, e2292. PubMed http://dx.doi.org/10.1136/bmj.e2292

Tan-Torres Edejer, T., Baltussen, R., Adam, T., Hutubessy, R., Acharya, A., Evans, D. B., \& Murray, C. J. L. (Eds.) (2003). Making Choices in Health: WHO Guide to CostEffectiveness Analysis. Geneva, Switzerland: World Health Organization. 


\section{Appendix}

Exhibit A1. NICU Costs by Gestational Age, 2008

\begin{tabular}{ccc}
\hline $\begin{array}{l}\text { Gestational } \\
\text { Age }\end{array}$ & Average Charge & $\begin{array}{c}\text { Neonates in Group with } \\
\text { Special Care Days/ Charges }\end{array}$ \\
\hline 33 & $\$ 70,029$ & $95.1 \%$ \\
34 & $\$ 52,890$ & $89.3 \%$ \\
35 & $\$ 41,000$ & $50.5 \%$ \\
36 & $\$ 35,627$ & $29.7 \%$ \\
37 & $\$ 33,665$ & $14.9 \%$ \\
38 & $\$ 29,523$ & $9.5 \%$ \\
39 & $\$ 26,019$ & $7.7 \%$ \\
40 & $\$ 26,010$ & $8.3 \%$ \\
41 & $\$ 23,140$ & $9.6 \%$ \\
42 & $\$ 27,467$ & $11.9 \%$ \\
$43+$ & $\$ 87,828$ & $13.2 \%$ \\
\hline
\end{tabular}

SOURCE: Personal Communication with Janet Muri, National Perinatal Information Center, 2011. 